\title{
Natural populations of lactic acid bacteria isolated from vegetable residues and silage fermentation
}

\author{
J. Yang, ${ }^{*} \dagger$ Y. Cao, ${ }^{*}$ Y. Cai, ${ }^{* 1}$ and F. Terada* \\ *National Institute of Livestock and Grassland Science, Nasushiobara, Tochigi 329-2793, Japan \\ †Hainan University, Haikou, Hainan 570228, China
}

\begin{abstract}
Natural populations of lactic acid bacteria (LAB) and silage fermentation of vegetable residues were studied. Fifty-two strains of LAB isolated from cabbage, Chinese cabbage, and lettuce residues were identified and characterized. The LAB strains were gram-positive and catalase-negative bacteria, which were divided into 6 groups (A to F) according to morphological and biochemical characteristics. The strains in group A were rods that did not produce gas from glucose and formed the D and L isomers of lactate. Groups B and $\mathrm{C}$ were homofermentative cocci that formed L-lactic acid. Groups D, E, and F were heterofermentative cocci that formed D-lactic acid. Based on $16 \mathrm{~S}$ rDNA gene sequence analysis, group A to $\mathrm{F}$ strains were identified as Lactobacillus plantarum, Lactococcus piscium, Lactococcus lactis, Leuconostoc citreum, Weissella soli and Leuconostoc gelidum, respectively. The prevalent LAB, predominantly homofermentative lactobacilli, consisted of Lactobacillus plantarum (34.6\%), Weissella soli $(19.2 \%)$, Leuconostoc gelidum (15.4\%), Leuconostoc citreum (13.5\%), Lactococcus lactis (9.6\%), and Lactococcus piscium (7.7\%). Lactobacillus plantarum was the dominant member of the LAB population in 3 types of vegetable residues. These vegetable residues contained a high level of crude protein (20.2 to $28.4 \%$ of dry matter). These silages prepared by using a smallscale fermentation system were well preserved, with low $\mathrm{pH}$ and a relatively high content of lactate. This study suggests that the vegetable residues contain abundant LAB species and nutrients, and that they could be well preserved by making silage, which is a potentially good vegetable protein source for livestock diets.
\end{abstract}

Key words: lactic acid bacteria, silage, vegetable residue

Received November 11, 2009.

Accepted March 17, 2010.

${ }^{1}$ Corresponding author: cai@affrc.go.jp

\section{INTRODUCTION}

Usually, food by-products contain high amounts of protein and fiber (Council for Science and Technology, 2005) suitable as animal feed. Vegetable residues as cabbage, Chinese cabbage, and lettuce contain abundant nutrients such as vitamins, minerals, and vegetable fiber (Council for Science and Technology, 2005), and large quantities of these vegetables are produced annually in many countries, including Japan.

These vegetable residues are easily perishable because of their high moisture content. Technologies to create good quality animal feed from vegetable residues and to provide long-term storage of the resulting silage need to be developed. Using vegetable residue silage as an animal feed has proven economically viable, not only as a way of disposing of vegetable residues but also as a real alternative for feeding livestock in regions where vegetable residues are the main food by-product. Lactic acid bacteria $(\mathbf{L A B})$ are naturally present on the surface of forage crops, grasses, and some vegetables (Cai et al., 1999b; Ennahar et al., 2003). They are responsible for silage fermentation and influence fermentation quality (Cai et al., 1998, 1999a; Cai, 1999).

The objective of the present study was to screen, isolate, and identify the LAB from vegetable residues, with particular interest in species that are most likely to play an important role in the fermentation process. Isolates were identified at the molecular level using $16 \mathrm{~S}$ rDNA sequence analysis. To use the vegetable residues effectively for animal feed, their chemical composition and silage fermentation characteristics were also studied.

\section{MATERIALS AND METHODS}

\section{Vegetable Residue Samples}

The vegetable residues of cabbage, Chinese cabbage, and lettuce (3 samples of each) were collected from a local commercial vegetable factory (Fujiyama factory, Matsuya Foods Co. Ltd., Fujinomiya, Shizuoka, Japan). The vegetable residue is the outside leaf part of cabbage (Brassica campestris L. var. capitata), Chinese 
cabbage (Brassica rapa L. var. glara Regel), and lettuce (Lactuca sativa L.) without addition of bacteria.

\section{Microbiological Analysis and LAB Isolates}

Vegetable residue samples (10 g) were blended with $90 \mathrm{~mL}$ of sterilized water and serially diluted $\left(10^{-1}\right.$ to $10^{-5}$ ) in sterilized water. The numbers of LAB were measured by plate count on lactobacilli deMan, Rogosa, Sharpe agar (MRS; Difco Laboratories, Detroit, MI) incubated at $30^{\circ} \mathrm{C}$ for $48 \mathrm{~h}$ under anaerobic conditions (anaerobic box, TE-HER Hard Anaerobox, ANX-1, Hirosawa Ltd., Tokyo, Japan). Coliform bacteria were counted on blue light broth agar (Nissui Ltd., Tokyo, Japan) incubated at $30^{\circ} \mathrm{C}$ for $48 \mathrm{~h}$; molds and yeasts were counted on potato dextrose agar (Nissui Ltd.) incubated for $24 \mathrm{~h}$ at $30^{\circ} \mathrm{C}$. Yeasts were distinguished from molds or bacteria by colony appearance and observation of cell morphology. Bacilli and aerobic bacteria were distinguished by colony shape and counted on nutrient agar (Nissui Ltd.) incubated for $24 \mathrm{~h}$ at $30^{\circ} \mathrm{C}$ under aerobic conditions. Colonies were counted as viable numbers of microorganisms in colony-forming units per gram of fresh matter (FM). Each LAB colony was purified twice by streaking on MRS agar. The purified strains were stored at $-80^{\circ} \mathrm{C}$ in nutrient broth (Difco) and dimethyl sulfoxide in a ratio of 9:1 for further analysis (Cai et al., 1999c,d).

\section{Morphological, Physiological, and Biochemical Tests}

Gram stain of LAB and morphological characteristics were determined after $24 \mathrm{~h}$ of incubation on MRS agar. Catalase activity and gas production from glucose were determined as described previously (Kozaki et al., 1992). Growth at different temperatures was detected in MRS broth after incubation at 5 and $10^{\circ} \mathrm{C}$ for $10 \mathrm{~d}$, and at 45 and $50^{\circ} \mathrm{C}$ for $7 \mathrm{~d}$. Growth at $\mathrm{pH}$ 2.5, 3.0, 3.5, 4.0 , and 7.0 was observed in MRS broth after incubation at $30^{\circ} \mathrm{C}$ for $7 \mathrm{~d}$. Salt tolerance of LAB was tested in MRS broth containing 3.0 and $6.5 \% \mathrm{NaCl}$. Carbohydrate assimilation and fermentation of 49 compounds with one control were identified on API $50 \mathrm{CH}$ strips (bioMérieux, Tokyo, Japan; Duan et al., 2008).

\section{S rRNA Gene Sequence Analysis}

Cells grown for $8 \mathrm{~h}$ in MRS broth at $30^{\circ} \mathrm{C}$ were used for DNA extraction and purification (Tamaoka and Komagata, 1984). The $16 \mathrm{~S}$ rRNA sequence coding region was amplified by PCR and performed in a PCR ThermalCycler (GenAmp PCR System 9700, PE Applied Biosystems, Foster City, CA) and reagents from a Takara Taq PCR Kit (Takara Shuzo Co. Ltd., Otsu,
Japan; Cai et al., 1998). Sequencing was performed twice on both strands by the dideoxy method using a Prism BigDye Terminator Cycle Sequence Ready Reaction Kit (Applied Biosystems) in combination with an Applied Biosystems model 310A automated sequencing system. Searching 16S rRNA gene sequence similarity was performed by using GenBank data library and the BLAST program (http://blast.ncbi.nlm.nih.gov/Blast. cgi). Then, the sequence information was introduced into the CLUSTAL W software program (http://www. ebi.ac.uk/Tools/clustalw2/index.html; Hitachi Software Engineering Co., Tokyo, Japan) for assembly and alignment (Thompson et al., 1994). The 16S rRNA gene sequences of isolates were compared with sequences from the type strains of LAB held in GenBank. Nucleotide substitution rates were calculated (Kimura and Ohta, 1972), and phylogenetic trees were constructed by the neighbor-joining (NJ) method (Saitou and Nei, 1987). Bacillus subtilis NCDO 1769 was used as an outgroup organism (Duan et al., 2008). The topologies of trees were evaluated by bootstrap analysis of the sequence data with CLUSTAL W software based on 100 random resamplings (Thompson et al., 1994).

\section{Nucleotide Sequence Accession Number}

The nucleotide sequences for the $16 \mathrm{~S}$ rRNA gene described in this report were deposited with GenBank under accession nos. AB485950, AB485951, AB485952, AB485953, AB485954, AB485955, AB485956, AB485957, and AB485958 for the representative strains NJ 116, NJ 119, NJ 316, NJ 121, NJ 314, NJ 123, NJ 124, NJ 314, and NJ 319, respectively.

\section{Laboratory Silage Preparation}

Silages were prepared using a small-scale system of silage fermentation (Cai et al., 1998). Approximately $100-\mathrm{g}$ portions of forage material, chopped into about 20-mm lengths, were packed into plastic film bags (Hiryu KN type, $180 \times 260 \mathrm{~cm}$, Asahikasei, Tokyo, Japan) and the bags sealed with a vacuum sealer (BH 950, Matsushita, Tokyo, Japan). The film bag silos were stored outdoors at 10.3 to $31.6^{\circ} \mathrm{C}$ for $60 \mathrm{~d}$ of fermentation. Three silos per treatment were used for chemical analysis.

\section{Chemical Analysis}

Cabbage, Chinese cabbage, and lettuce samples were dried in a forced-air oven at $65^{\circ} \mathrm{C}$ for $48 \mathrm{~h}$ and ground to pass a 1-mm screen with a Wiley mill (ZM200, Retsch GmbH \& Co. KG, Haan, Germany). Contents of DM, CP, ether extract, and OM were analyzed ac- 
cording to methods 934.01, 976.05, 920.39, and 942.05, respectively, of AOAC (1990). Neutral detergent fiber was analyzed with a thermostable amylase and sodium sulfite and ADF was analyzed nonsequentially; results were expressed without residual ash (Van Soest et al., 1991). Fermentation products of the vegetable residue silages were determined from cold-water extracts. Wet silage $(10 \mathrm{~g})$ was homogenized with $90 \mathrm{~mL}$ of sterilized distilled water (Cai et al., 1999b). The $\mathrm{pH}$ was measured with a glass electrode $\mathrm{pH}$ meter (MP230, Mettler Toledo, Greifensee, Switzerland), and ammonia-N was determined by steam distillation of the filtrates ( $\mathrm{Xu}$ et al., 2007). The organic acid contents were measured by HPLC (Jasco, Tokyo, Japan,) according to the methods described by Cai et al. (1999b). Water-soluble carbohydrates (WSC) including glucose, sucrose, and fructose were determined by HPLC (Jasco). The analytical conditions were as follows: column, Shodex Sugar SC1011 $(8.0 \mathrm{~mm} \times 30 \mathrm{~cm}$, Shoko, Tokyo, Japan); oven temperature, $80^{\circ} \mathrm{C}$; mobile phase, water; detector, $1.0 \mathrm{~mL} / \mathrm{min}$; detector, Jasco RI-1530.

\section{Statistical Analyses}

Data on chemical composition and silage quality of vegetable residues were subjected to ANOVA, and differences between means were assessed by Tukey test using the GLM procedure of SAS (SAS Institute Inc., Cary, NC).

\section{RESULTS}

\section{Counts of Microorganisms, Chemical Composition, and Silage Fermentation of Vegetable Residues}

The counts of viable microorganisms, chemical composition, and silage fermentation of vegetable residues are shown in Table 1. Overall, $10^{3}$ to $10^{4}$ ( $\mathrm{cfu} / \mathrm{g}$ of FM) $\mathrm{LAB}, 10^{3}$ to $10^{5}$ coliform bacteria, $10^{6}$ to $10^{7}$ aerobic bacteria, and $10^{3}$ to $10^{4}$ yeast were found in the 3 types of vegetable residue samples. Bacilli were found at $10^{3}$ in cabbage and lettuce, but could not be found in the Chinese cabbage. Molds were too few to be counted in all vegetable residue samples. Lactobacilli were $10^{3}$ to $10^{4} \mathrm{cfu} / \mathrm{g}$ of $\mathrm{FM}$ in the 3 types of vegetable residues. Cabbage and lettuce contained about $10^{3}$ leuconostocs, and Chinese cabbage and lettuce contained $10^{3}$ lactococci and $10^{3}$ weissella, respectively.

The moisture contents of all vegetable residues were high, ranging 94.2 to $97.1 \%$. Chinese cabbage and lettuce had a higher $(P<0.05) \mathrm{CP}$ content than cabbage, whereas cabbage and lettuce had a higher $(P<0.05)$ OM than Chinese cabbage. Cabbage and Chinese cabbage had a higher $\operatorname{ADF}(P<0.05)$ than lettuce, but had a similar content of NDF. Total WSC for cabbage was $20.5 \%$, higher $(P<0.05)$ than that of Chinese cabbage, which was similar to that of lettuce. All silages were well preserved, with a low $\mathrm{pH}$ and no detectable levels of butyric and propionic acids. The lactic acid content for cabbage silage was similar to that of Chinese cabbage silage and higher $(P<0.05)$ than that of lettuce silage.

\section{Morphological, Physiological, and Biochemical Properties}

Cell forms, characteristics, and API $50 \mathrm{CH}$ fermentation patters of representative strains isolated from vegetable residues are shown in Tables 2 and 3. All isolates were gram-positive and catalase-negative bacteria; they were unable to grow at $50^{\circ} \mathrm{C}$ but able to grow at $\mathrm{pH} 4.0$ to 7.0 and at $45^{\circ} \mathrm{C}$. According to the morphological, physiological, and biochemical properties, those strains were divided into 6 groups (A to F). Group A (representative strain: NJ 116) comprised homofermentative rods that did not produce gas from glucose and formed the DL isomer of lactate. Strains in group A were able to grow at the lowest $\mathrm{pH}(3.5)$ and produced the highest lactic acid content $(1.4 \%)$ in MRS broth compared with other groups. The phenotypic characteristics of group B (NJ 119) were similar to those of group C (NJ 316); these strains were homofermentative cocci that formed the $\mathrm{L}(+)$ isomer of lactate. Group B strains produced acid from L-arabinose, melezitose, and D-turanose and did not produce acid from ribose and D-xylose, which made it different from group C. Strains in group D (NJ 121 and NJ 314), group E (NJ 123 and NJ 124), and group F (NJ 315 and NJ 319) included heterofermentative cocci that formed the $\mathrm{D}(-)$ isomer of lactate. Group E did not produce acid from D-fructose, D-mannose, and D-turanose, and was different from groups D and F. Group D produced acid from arbutin and did not produce it from ribose, with the 2 fermentation patterns in group $\mathrm{F}$ being different. On the other hand, groups D, E, and F each included 2 strains that displayed some marked differences in some characteristics of growth 10 or $45^{\circ} \mathrm{C}$, and in 3.0 or $6.5 \%$ $\mathrm{NaCl}$.

\section{S rRNA Gene Sequence Analysis}

Phylogenetic trees are shown in Figures 1 and 2. Following phylogenetic analysis, the group A strain NJ116 was assigned to the genus Lactobacillus, because it grouped on the phylogenetic tree together with Lactobacillus pentosus, Lactobacillus plantarum, Lactobacillus paraplantarum, and Lactobacillus arizonensis in a $83 \%$ bootstrap cluster. Furthermore, NJ116 appeared to be 
Table 1. Microbiological analysis (viable microorganisms in fresh matter, FM), chemical composition, and silage quality of vegetable residues ${ }^{1}$

\begin{tabular}{|c|c|c|c|c|}
\hline Item & Cabbage & Chinese cabbage & Lettuce & SEM \\
\hline \multicolumn{5}{|l|}{ Counts (cfu/g of FM) } \\
\hline Lactic acid bacteria & $4.4 \times 10^{4}$ & $4.7 \times 10^{3}$ & $5.0 \times 10^{3}$ & \\
\hline Bacilli & $4.5 \times 10^{3}$ & $\mathrm{ND}^{2}$ & $1.5 \times 10^{3}$ & \\
\hline Coliform bacteria & $6.5 \times 10^{5}$ & $7.0 \times 10^{3}$ & $6.0 \times 10^{4}$ & \\
\hline Aerobic bacteria & $3.7 \times 10^{6}$ & $2.5 \times 10^{7}$ & $3.7 \times 10^{6}$ & \\
\hline Molds & ND & ND & ND & \\
\hline Yeasts & $1.4 \times 10^{4}$ & $3.0 \times 10^{3}$ & $1.5 \times 10^{3}$ & \\
\hline Lactobacilli & $3.5 \times 10^{4}$ & $3.0 \times 10^{3}$ & $1.0 \times 10^{3}$ & \\
\hline Lactococci & ND & $2.0 \times 10^{3}$ & ND & \\
\hline Leuconostoc & $8.2 \times 10^{3}$ & ND & $1.0 \times 10^{3}$ & \\
\hline Weissella & ND & ND & $3.5 \times 10^{3}$ & \\
\hline \multicolumn{5}{|c|}{ Chemical composition (\% of DM) } \\
\hline OM & $88.7^{\mathrm{a}}$ & $82.2^{\mathrm{b}}$ & $87.3^{\mathrm{a}}$ & 0.77 \\
\hline $\mathrm{CP}$ & $20.2^{\mathrm{b}}$ & $28.4^{\mathrm{a}}$ & $27.7^{\mathrm{a}}$ & 0.66 \\
\hline Ether extract & $6.1^{\mathrm{a}}$ & $3.4^{\mathrm{b}}$ & $2.5^{\mathrm{b}}$ & 0.18 \\
\hline $\mathrm{ADF}$ & $29.9^{\mathrm{a}}$ & $26.4^{\mathrm{a}}$ & $21.0^{\mathrm{b}}$ & 0.57 \\
\hline NDF & 31.4 & 28.4 & 30.7 & 0.78 \\
\hline Glucose & $9.2^{\mathrm{a}}$ & $4.0^{\mathrm{b}}$ & $3.8^{\mathrm{b}}$ & 0.11 \\
\hline Fructose & $9.1^{\mathrm{b}}$ & $9.4^{\mathrm{ab}}$ & $10.4^{\mathrm{a}}$ & 0.36 \\
\hline Sucrose & $2.2^{\mathrm{a}}$ & $1.8^{\mathrm{a}}$ & $0.9^{\mathrm{b}}$ & 0.64 \\
\hline \multicolumn{5}{|l|}{ Silage quality } \\
\hline Moisture content (\%) & $94.2^{\mathrm{b}}$ & $97.1^{\mathrm{a}}$ & $95.8^{\mathrm{ab}}$ & 0.35 \\
\hline $\mathrm{pH}$ & $3.6^{\mathrm{b}}$ & $3.9^{\mathrm{a}}$ & $3.8^{\mathrm{a}}$ & 0.01 \\
\hline Lactic acid (\% of DM) & $24.5^{\mathrm{a}}$ & $24.8^{\mathrm{a}}$ & $14.8^{\mathrm{b}}$ & 0.10 \\
\hline Acetic acid (\% of DM) & $8.3^{\mathrm{a}}$ & $6.9^{\mathrm{ab}}$ & $4.8^{\mathrm{b}}$ & 0.07 \\
\hline Butyric acid (\% of DM) & ND & ND & $\mathrm{ND}$ & \\
\hline Propionic acid (\% of DM) & ND & ND & ND & \\
\hline Ammonia-N (\% of DM) & $3.6^{\mathrm{b}}$ & $9.0^{\mathrm{a}}$ & $3.6^{\mathrm{b}}$ & 0.05 \\
\hline
\end{tabular}

${ }^{\mathrm{a}, \mathrm{b}}$ Means within rows with different superscripts differ $(P<0.05)$.

${ }^{1}$ Silage was stored for $60 \mathrm{~d}$; data are the average of 3 vegetable residue samples.

${ }^{2}$ Not detected.

equally linked ( $64 \%$ bootstrap) to both $L b$. plantarum and $L b$. pentosus, and its $16 \mathrm{~S}$ rDNA sequence showed a similarity of $99.3 \%$ to $L b$. plantarum and $99.2 \%$ to $L b$. pentosus. Group B strain NJ 119 and group C strain NJ 316 were placed in the cluster of genus Lactococcus, which was recovered in $100 \%$ of bootstrap analyses (Figure 2). They formed a distinct cluster with Lactococcus piscium and Lactococcus lactis subspecies group, supported with a bootstrap value of $100 \%$. Although NJ 119 was monophyletic with Lc. piscium with a bootstrap of $100 \%$, NJ 316 grouped with 2 subspecies: Lc. lactis ssp. cremoris and Lc. lactis ssp. lactis, in a $100 \%$ bootstrap cluster, and its $16 \mathrm{~S}$ rDNA sequence showed a similarity of over $99.8 \%$ to the 2 subspecies. Groups D and F were placed in the cluster making up the genus Leuconostoc, together with Leuconostoc citreum and Leuconostoc gelidum. Strains NJ 121 and NJ 314 of group D were closely related to Ln. citreum species in $100 \%$ of bootstrap analyses. Strains NJ 315 and NJ 319 of group F were both placed in the cluster of Leuconostoc, and Ln. gelidum was the most closely related species. The group E strains (NJ 123 and NJ 124) were placed in the Weissella cluster, because they grouped on the phylogenetic tree with Weissella soli. In group E, W. soli was the most closely related species in $100 \%$ of bootstrap analyses.

\section{DISCUSSION}

Generally, LAB are found living in association with plant material and dairy products, and several studies have reported $\mathrm{LAB}$ as the dominant microbial population on forage crops and silage (Cai et al., 1999c; Ennahar and Cai, 2004; Duan et al., 2008). Some isolates from forage crops and grasses have been identified as species of lactobacilli, enterococci, pediococci, weissella, lactococci, and leuconostocs. Cai et al. (1998, 1999a,b) examined a large number of forage crops and grasses and found that the predominant LAB were lactic acid-producing cocci and that the least numerous were lactobacilli (mostly homofermentative). Ennahar et al. (2003) also found that although all LAB groups were present in paddy rice silage, homofermentative lactobacilli and lactococci and heterofermentative leuconostocs were present in higher numbers. In the present investigation, 120 strains isolated from vegetables were screened, of which 52 isolates were considered LAB as determined by culture on MRS agar, Gram stain 
Table 2. Characteristics of representative strains (neighbor-joining method or NJ designations) isolated from vegetable residues ${ }^{1}$

\begin{tabular}{|c|c|c|c|c|c|c|c|c|c|}
\hline Characteristic & $\frac{\text { Group A }}{\text { NJ } 116}$ & $\frac{\text { Group B }}{\text { NJ } 119}$ & $\frac{\text { Group C }}{\text { NJ } 316}$ & \multicolumn{2}{|c|}{ Group D } & \multicolumn{2}{|c|}{ Group E } & \multicolumn{2}{|c|}{ Group F } \\
\hline No. of isolates & 18 & 4 & 5 & 4 & 3 & 5 & 5 & 3 & 5 \\
\hline Gram stain & + & + & + & + & + & + & + & + & + \\
\hline Catalase & - & - & - & - & - & - & - & - & - \\
\hline Gas from glucose & - & - & - & + & + & + & + & + & + \\
\hline Fermentation type & Homo & Homo & Homo & Hetero & Hetero & Hetero & Hetero & Hetero & Hetero \\
\hline Optical form of lactate & DL & $\mathrm{L}(+)$ & $\mathrm{L}(+)$ & $\mathrm{D}(-)$ & $\mathrm{D}(-)$ & $\mathrm{D}(-)$ & $\mathrm{D}(-)$ & $\mathrm{D}(-)$ & $\mathrm{D}(-)$ \\
\hline \multicolumn{10}{|l|}{ Growth at temperature $\left({ }^{\circ} \mathrm{C}\right)$} \\
\hline 5.0 & - & - & - & - & - & - & - & - & - \\
\hline 10.0 & + & $\mathrm{w}$ & - & $\mathrm{w}$ & + & $\mathrm{w}$ & - & - & - \\
\hline 45.0 & + & + & + & $\mathrm{w}$ & + & $\mathrm{w}$ & + & + & $\mathrm{w}$ \\
\hline 2.5 & - & - & - & - & - & - & - & - & - \\
\hline 3.0 & $\mathrm{w}$ & - & - & - & - & - & - & - & - \\
\hline 3.5 & + & $\mathrm{w}$ & $\mathrm{w}$ & - & $\mathrm{w}$ & - & - & - & - \\
\hline 4.0 & + & + & + & + & + & + & + & + & + \\
\hline 7.0 & + & + & + & + & + & + & + & + & + \\
\hline 16S rDNA similarity ${ }^{3}(\%)$ & 99.30 & 99.80 & 99.90 & 99.50 & 99.40 & 99.00 & 99.70 & 99.40 & 99.30 \\
\hline
\end{tabular}

${ }^{1}+=$ positive; $\mathrm{w}=$ weakly positive; $-=$ negative.

${ }^{2} \mathrm{MRS}=$ de Man, Rogosa, and Sharpe broth.

${ }^{3} 16 \mathrm{~S}$ rDNA sequence similarity between isolate and each type strain was analyzed by BLAST search program. Type strains are Lactobacillus plantarum JCM1149 ${ }^{\mathrm{T}}$, Lactococcus piscium JCM $16647^{\mathrm{T}}$, Lactococcus lactis JCM5805 ${ }^{\mathrm{T}}$, Leuconostoc citreum $\mathrm{JCM} 9698^{\mathrm{T}}$, Weissella soli $\mathrm{JCM}$ $12536^{\mathrm{T}}$ and Leuconostoc gelidum $\mathrm{JCM} 9697^{\mathrm{T}}$. JCM = Japan Collection of Microorganisms; ${ }^{\mathrm{T}}=$ Type strains.

appearance, catalase test, and lactic acid production from glucose. All of the presumptive LAB were further characterized by sugar fermentation assays using API $50 \mathrm{CH}$ strips. This led to delineation of 6 groups of isolates, each displaying a distinct carbohydrate fermentation pattern (Table 3 ). The various groups presumably represented 4 genera: Lactobacillus, Lactococcus, Weissella, and Leuconostoc. Lactobacilli were the dominant counts of the LAB population in 3 types of vegetable residues. Leuconostocs were mainly distributed in cabbage and lettuce, lactococci were mainly in Chinese cabbage, and weissella were mainly in lettuce. This is the first report of the identification of LAB from these vegetable residues.

The phenotypic procedure to assign isolates to known species is difficult, because it can be hard to differentiate between species. In an effort to identify LAB isolates at the species level, molecular phylogeny analysis was conducted and phylogenetic trees were constructed based on the 16S rDNA sequences from evolutionary distances by the neighbor-joining method. The representative strains of groups B (NJ 119), D (NJ 121 and NJ 314), E (NJ 123 and NJ 124), and F (NJ 315 and NJ 319) were identified as Lc. piscium, Ln. citreum, $W$. soli, and Ln. gelidum, respectively, by forming a very well-defined cluster with each type strain, supported with a $>99 \% 16 \mathrm{~S}$ rDNA similarity between the group representative strain and each type strain.

Group C strain NJ 316 was ascribed to Lc. lactis ssp. cremoris on the phylogenetic tree, with a bootstrap of $80 \%$, supporting monophyly. Nevertheless, as reported by some studies (Björkroth et al., 2002; Ennahar and Cai, 2004, 2005), the $16 \mathrm{~S}$ rDNA sequence analysis method, although very good at identifying the organisms by genus and species, cannot differentiate strains at the subspecies level and is therefore not an appropriate method to measure intraspecies relationships. Despite strain NJ 316 and Lc. lactis ssp. cremoris clustering together on the phylogenetic tree, NJ 316 and Lc. lactis ssp. lactis consistently did not show discrepancy with regard to sugar fermentation patterns.

In the same way, group A strain NJ 116 was phylogenetically identified as $L b$. plantarum or Lb. pentoses, and its $16 \mathrm{~S}$ rDNA sequence showed $>99.8 \%$ similarity to the 2 type strains. Ennahar et al. (2003) reported that the 2 species have very similar $16 \mathrm{~S}$ rDNA sequences that differ by only $2 \mathrm{bp}$. It is widely acknowledged that $L b$. plantarum and $L b$. pentosus belong to the same $16 \mathrm{~S}$ 
Table 3. Fermentation patterns (evaluated using API $50 \mathrm{CH}$ strips; bioMérieux, Tokyo, Japan) of lactic acid bacteria strains isolated from vegetable residues ${ }^{1}$

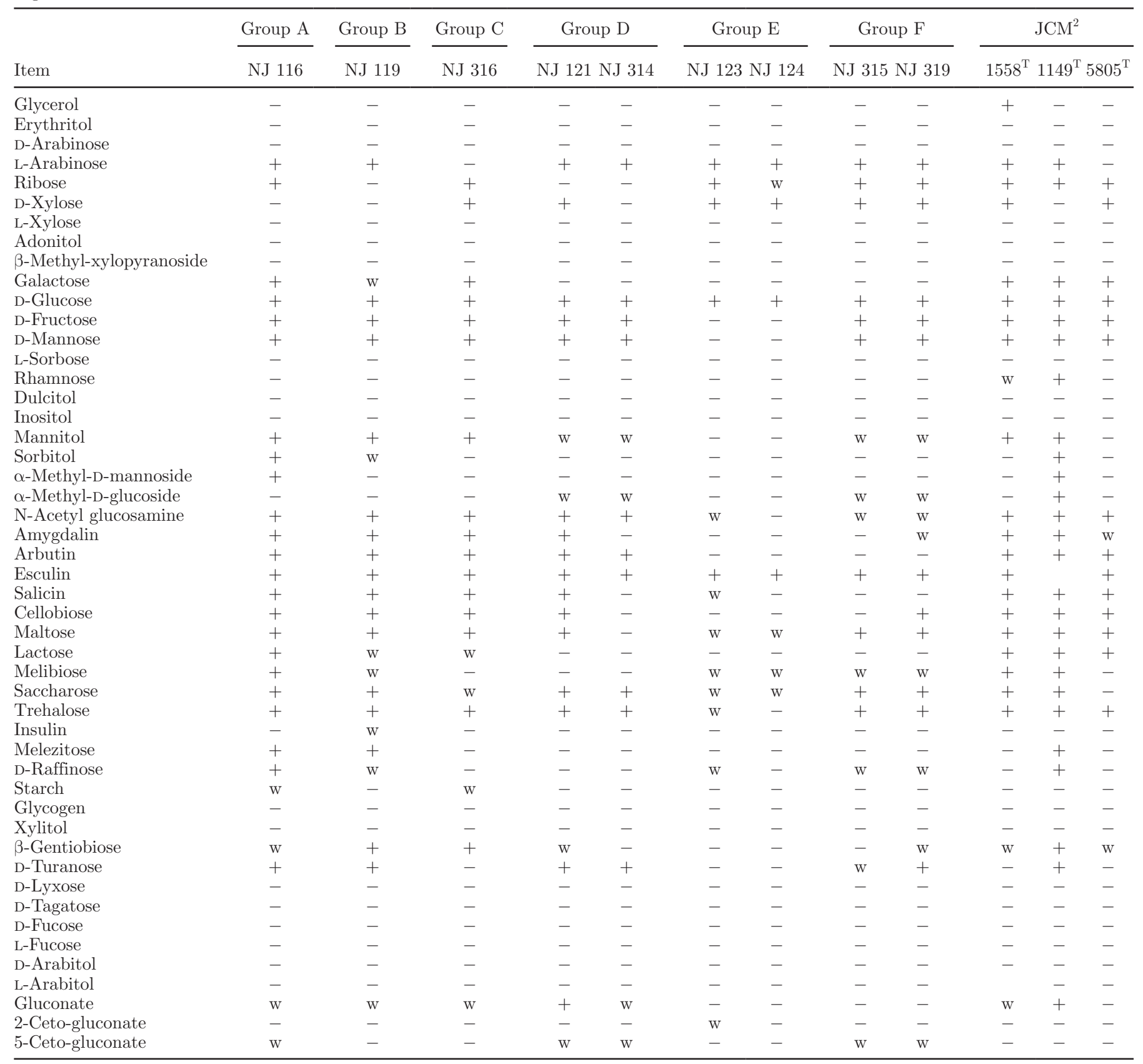

${ }^{1}+=$ positive; $\mathrm{w}=$ weakly positive; $-=$ negative.

${ }^{2}$ Japan Collection of Microorganisms; ${ }^{\mathrm{T}}=$ Type strains: JCM1149 = Lactobacillus plantarum; JCM1558 = Lactobacillus pentosus; JCM5805 = Lactococcus lactis.

rRNA phylogenetic group and can only be distinguished using phylogenetic analysis of sequences of the $16 \mathrm{~S}-23 \mathrm{~S}$ large space region (Hammes and Vogel, 1995) or partial sequences of the rec $A$ gene (Torriani et al., 2001). In the present study, we referred to carbohydrate fermentation patterns that showed unambiguously that the pattern of strain NJ 116 was an exact match of that of the $L b$. plantarum type strain and different from that of the $L b$. pentosus type strain. In fact, it appeared that, although the $L b$. plantarum type strain produced acid from melezitose, D-raffinose, and $\alpha$-methyl-D-mannoside, the $L b$. pentosus type strain did not. On the other hand, unlike Lb. plantarum, Lb. pentosus could grow using glycerol or D-xylose as a carbon source (Table 3). All 


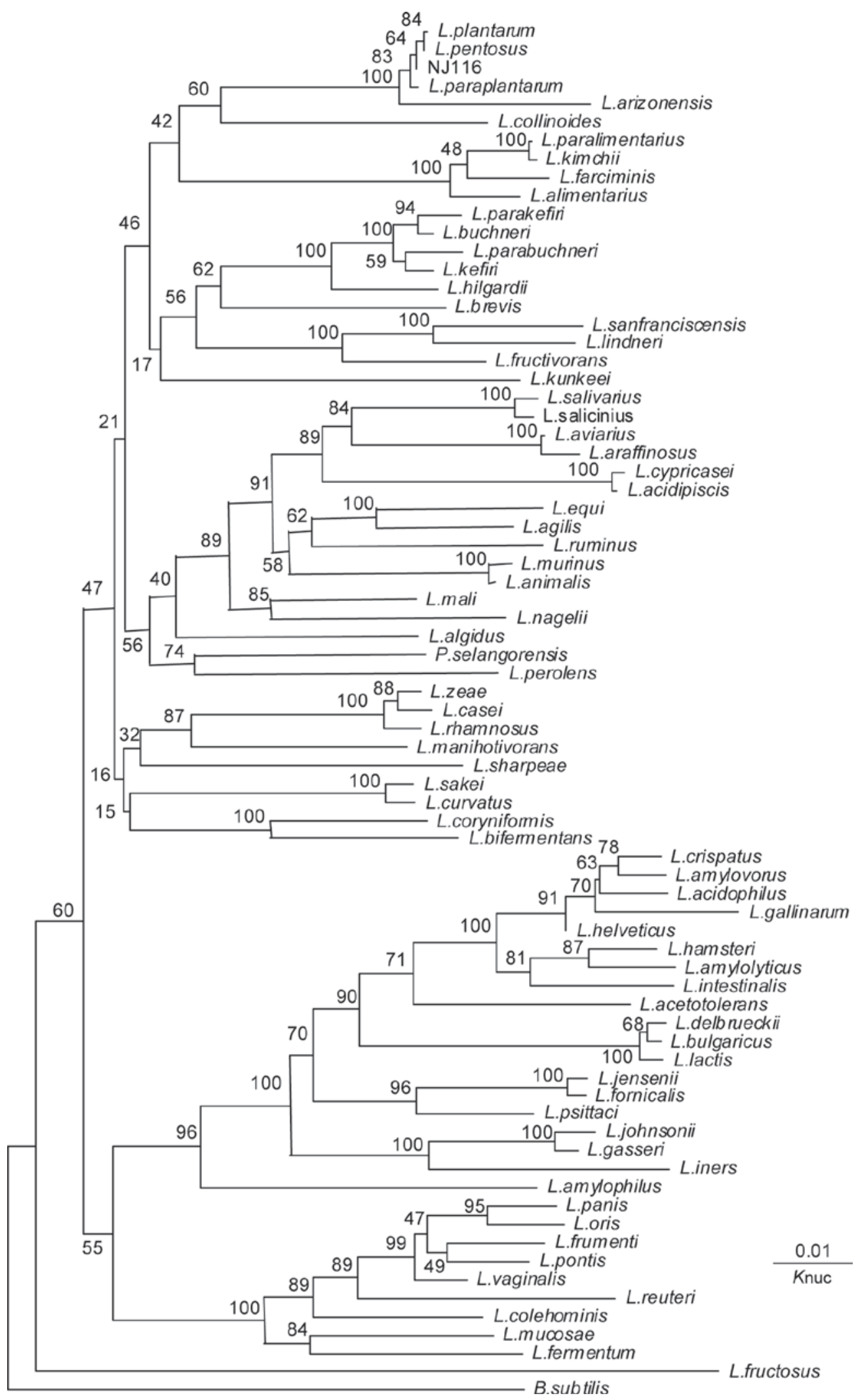

Figure 1. Phylogenetic tree showing the relative positions of vegetable residues isolates NJ116 as inferred by the neighbor-joining method of complete 16S rDNA sequences. Bootstrap values for 100 replicates are shown at the nodes of the tree. Bacillus subtilis is used as an outgroup. The bar indicates $1 \%$ sequence divergence. $L .=$ Lactobacillus; Knuc $=$ nucleotide substitution rate. 


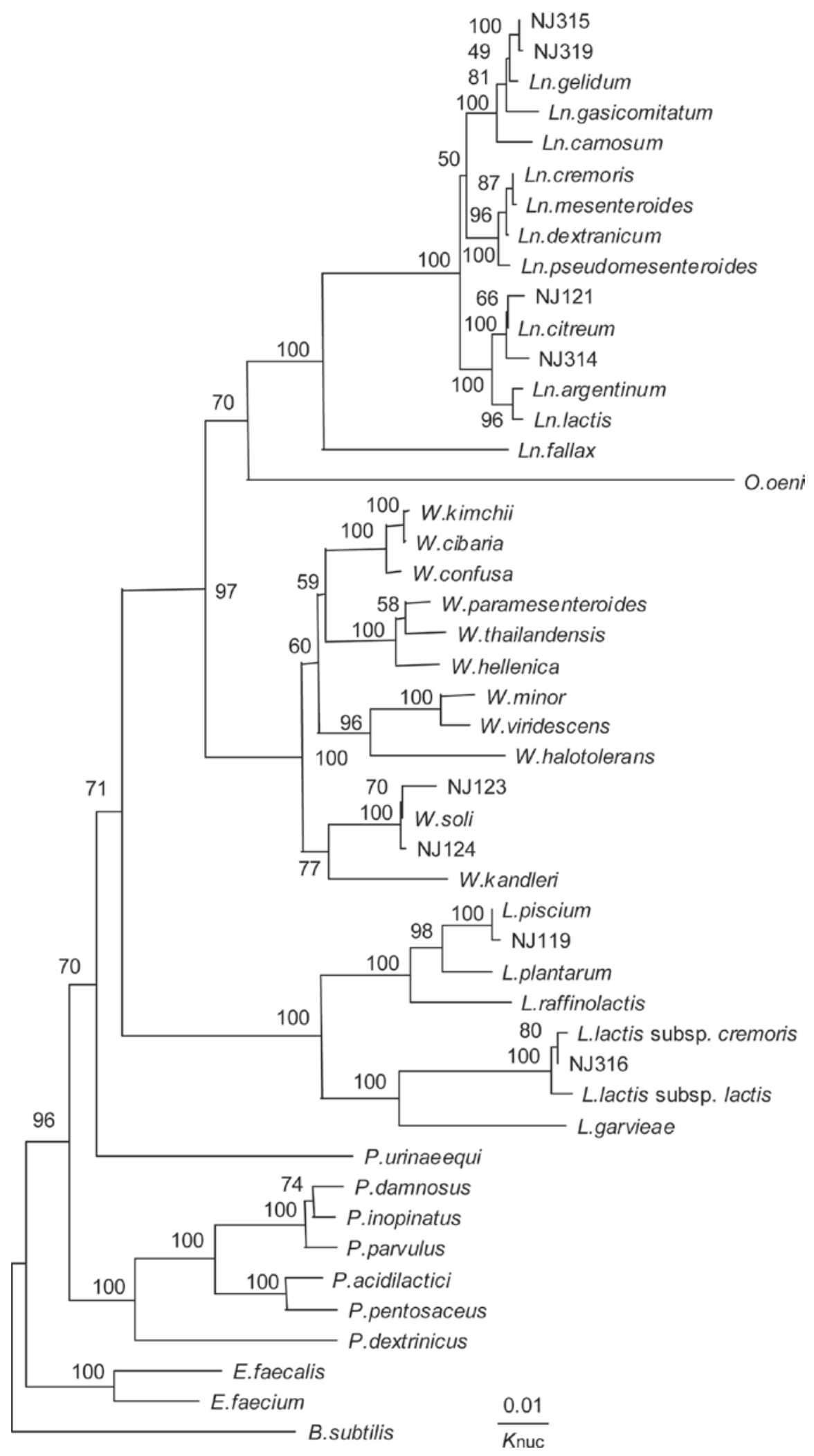

Figure 2. Phylogenetic tree showing the relative positions of vegetable residues isolates NJ 119, NJ 121, NJ 123, NJ 124, NJ 314, NJ 315, NJ 316, and NJ 319 as inferred by the neighbor-joining (NJ) method of complete $16 \mathrm{~S}$ rDNA sequences. Bootstrap values for 100 replicates are shown at the nodes of the tree. Bacillus subtilis is used as an outgroup. The bar indicates $1 \%$ sequence divergence. Ln. $=$ Leuconostoc; W. $=$ Weissella; L. $=$ Lactococcus P. $=$ Pediococcus; and E. = Enterococcus. Knuc $=$ nucleotide substitution rate. 
other isolates from group A were similarly identified as Lb. plantarum.

Phylogenetic trees based on the 16S rDNA sequence displayed high consistency regarding the relationships between the organisms included (Ennahar et al., 2003; Cho et al., 2008). All the nodes leading to NJ strain clusters are supported by high bootstrap values and should be considered significant. Also, NJ strains were designated to the correct species with close homology. The BLAST search analyses using the whole $16 \mathrm{~S}$ rDNA sequence resulted in identification at the $>99 \%$ level, and the cutoff value indicating species identity is considered to be above $97 \%$.

Following biochemical and phylogenetic analysis, NJ isolates fell within well-recognized groups of LAB, and most of the LAB characterized belonged to the genera Lactobacillus, Lactococcus, Weissella, and Leuconostoc. The species diversity was observed because 6 species were also identified: $L b$. plantarum $(34.6 \%)$, Lc. piscium (7.7\%), Lc. cremoris (9.6\%), Ln. citreum (13.5\%), Ln. gelidum (15.4\%), and W. soli (19.2\%). Furthermore, homofermentative species accounted for $53 \%$ of the total LAB microflora.

Some LAB species identified in vegetables are common inhabitants of a variety of forage crops and silages. This is in agreement with the results of our previous investigations (Cai et al., 1998, 1999b; Cai, 1999), as well as those of other authors (Lin et al., 1992; Sebastian et al., 1996), which showed that the natural fermentation processes in silage, including corn, sorghum, alfalfa, Italian ryegrass, forage paddy rice, and guinea grass silages, are dominated by species of Lactobacillus, Pediococcus, Leuconostoc, Weissella, and Lactococcus. The prevalent species in vegetable residues, $L b$. plantarum, is reportedly the most dominant during the fermentation of forage crops and grasses silages (Ennahar et al., 2003). Other LAB such as leuconostocs, pediococci, weissella, and enterococci have often been found at low frequencies together with Lactococcus strains on plant materials and in various silages (Cai, 1999; Cai et al., 1999d). They are also widely used as starter cultures or control barriers for food pathogens in vegetables (Vescovo et al., 1996). The presence of $W$. soli suggests a soil origin of some vegetable microorganisms. The natural habitat of lactococci is milk, but Lc. lactis ssp. lactis has been isolated previously from paddy rice, cereals, and forage crops (Ennahar et al., 2003).

It is well established that LAB play an important role in silage fermentation. The epiphytic LAB numbers have become a significant factor in predicting the adequacy of silage fermentation and determining whether to apply bacterial inoculants to silage materials (McDonald et al., 1991; Lin et al., 1992). The different species and the characteristics of epiphytic LAB might change and influence fermentation losses and silage quality (Lin et al., 1992). Among epiphytic LAB, lactic acid-producing cocci (e.g., enterococci, leuconostocs, weissella, pediococci, and lactococci) start lactic acid fermentation in silage. Some heterofermentative cocci produce gas from glucose and create an aerobic environment suitable for the development of lactobacilli only in the early stage of ensiling processes (Cai et al., 1998). In contrast to the lactic acid-producing cocci, lactobacilli (Rodhe, 1990) are important promoters of lactic acid fermentation for a longer fermentation period. Many studies (Cai et al., 1998, 1999b) have reported that the inoculation of forage with homofermentative lactobacilli such as Lactobacillus casei or Lb. plantarum has beneficial effects on promoting lactic acid fermentation and improving silage quality. However, the heterofermentative weissellas and leuconostocs did not improve silage quality and may have caused some fermentation loss (Cai et al., 1998). Generally, moist silage is based on a lactic acid fermentation. The epiphytic LAB transforms WSC into organic acid in the ensiling process. As a result, the $\mathrm{pH}$ is reduced and the forage is preserved (McDonald et al., 1991). In the present study, the vegetable residue silages of 3 types were well preserved, with high lactic acid contents and low $\mathrm{pH}$ values. The factors involved in assessing fermentation quality include the chemical composition of the vegetable residue material and the physiological properties of epiphytic bacteria. As shown in Table 1, these vegetable residues have relatively high WSC content of 15 to $20 \%$ on a DM basis and a high number of epiphytic lactobacilli $\left(10^{4} \mathrm{cfu} / \mathrm{g}\right.$ of FM). During silage fermentation, the lactobacilli could produce sufficient lactic acid to reduce $\mathrm{pH}$ and inhibit the growth of harmful bacteria; therefore, the resulting silage was of good quality.

The study suggests that vegetable residues contained many species of LAB and abundant nutritional content. Based on the silage fermentation and chemical composition analysis, we have found that the vegetable residue can be well preserved by preparing a silage and it has good potential as a vegetable protein source for livestock diets.

\section{ACKNOWLEDGMENTS}

This work was supported by the Research and Development Projects for Application in Promoting New Policy of Agriculture Forestry and Fisheries from the Ministry of Agriculture, Forestry and Fisheries in Japan. We thank Y. Ando (Fujiyama factory, Matsuya Foods Co. Ltd., Fujinomiya, Shizuoka, Japan) for providing the vegetable residue samples. 


\section{REFERENCES}

AOAC. 1990. Official Methods of Analysis. 15th ed. Association of Official Analytical Chemists, Arlington, VA.

Björkroth, K. J., U. Schillinger, R. Geisen, N. Weiss, B. Hoste, W. H. Holzapfel, H. J. Korkeala, and P. Vandamme. 2002. Taxonomic study of Weissella confusa and description of Weissella cibaria sp. nov., detected in food and clinical samples. Int. J. Syst. Evol. Microbiol. 52:141-148.

Cai, Y. 1999. Identification and characterization of Enterococcus species isolated from forage crops and their influence on silage fermentation. J. Dairy Sci. 82:2466-2471.

Cai, Y., Y. Benno, M. Ogawa, and S. Kumai. 1999a. Effect of applying lactic acid bacteria isolated from forage crops on fermentation characteristics and aerobic deterioration of silage. J. Dairy Sci. 82:520-526.

Cai, Y., Y. Benno, M. Ogawa, S. Ohmomo, S. Kumai, and T. Nakase. 1998. Influence of Lactobacillus spp. from an inoculant and of Weissella and Leuconostoc spp. from forage crops on silage fermentation. Appl. Environ. Microbiol. 64:2982-2987.

Cai, Y., S. Kumai, M. Ogawa, Y. Benno, and T. Nakase. 1999b. Characterization and identification of Pediococcus species isolated from forage crops and their application for silage preparation. Appl. Environ. Microbiol. 65:2901-2906.

Cai, Y., H. Okada, H. Mori, Y. Benno, and T. Nakase. 1999c. Lactobacillus paraalimentarius sp. nov. isolated from sourdough. Int. J. Syst. Bacteriol. 49:1451-1455.

Cai, Y., P. Suyanandana, P. Saman, and Y. Benno. 1999d. Classification and characterization of lactic acid bacteria isolated from the intestines of common carp and freshwater prawns. J. Gen. Appl. Microbiol. 45:177-184.

Cho, S. L., S. Nam, J. Yoon, J. Lee, A. Sukhoom, and W. Kim. 2008. Lactococcus chungangensis sp. nov., a lactic acid bacterium isolated from activated sludge foam. Int. J. Syst. Evol. Microbiol. $58: 1844-1849$.

Council for Science and Technology. 2005. Standard Tables of Food Composition in Japan. 5th ed. M. o. E., Culture, Sports, Science and Technology, Japan. National Printing Bureau, Tokyo, Japan.

Duan, Y., Z. Tan, Y. Wang, Z. Li, Z. Li, G. Qin, Y. Huo, and Y. Cai. 2008. Identification and characterization of lactic acid bacteria isolated from Tibetan Qula cheese. J. Gen. Appl. Microbiol. 54:51-60.

Ennahar, S., and Y. Cai. 2004. Genetic evidence that Weissella kimchii Choi et al. 2002 is a junior subjective synonym of Weissella cibaria Björkroth et al. 2002. Int. J. Syst. Evol. Microbiol. 54:463-465.

Ennahar, S., and Y. Cai. 2005. Biochemical and genetic evidence for the transfer of Enterococcus solitarius Collins et al. 1989 to the genus Tetragenococcus as Tetragenococcus solitarius comb. nov. Int. J. Syst. Evol. Microbiol. 55:589-592.

Ennahar, S., Y. Cai, and Y. Fujita. 2003. Phylogenetic diversity of lactic acid bacteria associated with paddy rice silage as determined by $16 \mathrm{~S}$ ribosomal DNA analysis. Appl. Environ. Microbiol. 69:444-451.

Hammes, W. P., and R. F. Vogel. 1995. The genus Lactobacillus. Pages $19-54$ in the Lactic Acid Bacteria. The Genera of Lactic Acid Bacteria. Vol. 2. B. J. B. Wood and W. H. Holzapfel, ed. Blackie Academic and Professional, London, UK.

Kimura, M., and T. Ohta. 1972. On the stochastic model for estimation of mutation distance between homologous proteins. J. Mol. Evol. 2:87-90.

Kozaki, M., T. Uchimura, and S. Okada. 1992. Page 34-37 in Experimental Manual of Lactic Acid Bacteria. Asakurashoten, Tokyo, Japan.

Lin, C., K. K. Bolsen, B. E. Brent, and D. Y. C. Fung. 1992. Epiphytic lactic acid bacteria succession during the pre-ensiling and ensiling periods of alfalfa and maize. J. Appl. Bacteriol. 73:375-387.

McDonald, P., N. Henderson, and S. Heron. 1991. The Biochemistry of Silage. 2nd ed. Chalcombe Publ., Marlow, UK.

Moon, N. J. 1983. Inhibition of the growth of acid tolerant yeasts by acetate, lactate and propionate and their synergistic mixtures. J Appl. Bacteriol. 54:453-460.

Rodhe, H. 1990. A comparison of the contribution of various gases to the greenhouse effect. Science 248:1217-1219.

Saitou, N., and M. Nei. 1987. The neighbor-joining method: A new method for reconstructing phylogenetic trees. Mol. Biol. Evol. 4:406-425.

Sebastian, S., L. E. Phillip, V. Fellner, and E. S. Idziak. 1996. Comparative assessment of bacterial inoculated corn and sorghum silages. J. Anim. Sci. 71:505-514.

Tamaoka, J., and K. Komagata. 1984. Determination of DNA base composition by reversed-phase high-performance liquid chromatography. FEMS Microbiol. Lett. 124:11-16.

Thompson, J. D., D. G. Higgins, and T. J. Gibson. 1994. CLUSTAL $\mathrm{W}$ : Improving the sensitivity of progressive multiple sequence alignment through sequence weighting, position-specific gap penalties and weight matrix choice. Nucleic Acids Res. 22:46734680.

Torriani, S., G. E. Felis, and F. Dellaglio. 2001. Differentiation of Lactobacillus plantarum, L. pentosus, and L. paraplantarum by recA gene sequence analysis and multiplex PCR assay with recA gene-derived primers. Appl. Environ. Microbiol. 67:3450-3454.

Van Soest, P. J., J. B. Robertson, and B. A. Lewis. 1991. Methods for dietary fiber, neutral detergent fiber, and non-starch polysaccharides in relation to animal nutrition. J. Dairy Sci. 74:3583-3597.

Vescovo, M., S. Torriani, C. Orsi, F. Macchiarolo, and G. Scolari. 1996. Application of antimicrobial-producing lactic acid bacteria to control pathogens in ready-to-use vegetables. J. Appl. Bacteriol. 81:113-119.

Xu, C. C., Y. Cai, J. Zhang, and M. Ogawa. 2007. Fermentation quality and nutritive value of total mixed ration silage containing coffee grounds at ten or twenty percent of dry matter. J. Anim. Sci. 85:1024-1029. 